\title{
HERBIVOROUS INSECTS COLONISING CYANOGENIC AND ACYANOGENIC TRIFOLIUM REPENS
}

\author{
W. DRITSCHILO', J. KRUMMEL*, D. NAFUS** and D. PIMENTEL*
}

Center for the Biology of Natural Systems, Washington University, St Louis, Missouri 63130 and - Department of Entomology and Section of Ecology and Systematics, Cornell University, Ithaca, New York 14853

Received 21.vi.78

\section{SUMMARY}

\begin{abstract}
Insect herbivores colonizing cyanogenic and acyanogenic white clover plants were investigated. With the exception of aphids, the herbivores studied were infrequent visitors and failed to discriminate between the two phenotypes. Aphids, however, were two to three times more abundant on acyanogenic than cyanogenic plants. Evidence of visible insect feeding damage was identical for both phenotypes. The evidence suggests that the trait of cyanogenesis confers protection against herbivory by aphids and, possibly, other insects. Such protection would be most important at the seedling stage, but feeding of the insects studied would not lead directly to seedling mortality of either phenotype. Instead, mortality of weakened seedlings may result from other causes later in the season.
\end{abstract}

\section{Introduction}

THE ability of a plant to produce hydrogen cyanide upon damage from herbivore feeding can confer protection against insect herbivores (CooperDriver and Swain, 1976; Bernays et al., 1977; Woodhead and Bernays, 1977). Cyanogenesis in the polymorphic species Trifolium repens L. and Lotus corniculatus $\mathrm{L}$. has been shown to inhibit feeding by vertebrates and molluscs (Jones, 1962, 1966; Crawford-Sidebotham, 1972; Angseesing, 1974.) Lepidoptera species studied, however, failed to select for either acyanogenic or cyanogenic Lotus corniculatus, nor were there any differences in the growth characteristics of larvae reared on the two forms (Lane, 1962; Jones, 1966; Scriber, 1978). Miller et al. (1975) found no differences in seedling mortalities of cyanogenic and acyanogenic phenotypes of white clover (Trifolium repens) subject to uncontrolled herbivory by insects.

In view of cyanide's well-known toxicity to insects, further work focusing on insect herbivores appears appropriate. This report compares insect damage and population levels of some colonising phytophagous insects on cyanogenic and acyanogenic white clover.

\section{MAterial AND MEthods}

Cuttings were obtained of wild white clover plants from several similar habitats in Tompkins County, New York. Care was taken that, of the

${ }^{1}$ Present address: Environmental Science and Engineering, UCLA, Los Angeles, California 90024. ${ }^{2}$ Agricultural Research Center East, USDA, Beltsville, Maryland 20705. 
cyanogenic plants, only those producing the most intense colour in the picrate reagent test were included. Plants were propagated vegetatively from the cuttings and grown in a glasshouse.

An abandoned pasture in Tompkins County, New York, was the site of the experiments. Four $8 \mathrm{~m}^{2}$ plots, situated $100 \mathrm{~m}$ apart, were cleared of vegetation and planted with the white clover strains grown in the glasshouse. Two of the plots had cyanogenic plants exclusively and the other two plots, acyanogenic plants. In 1975, clover (16-18 plants per plot) was transplanted directly to the soil and allowed to grow in a normal manner while being colonised by insects. The plants were $15-25 \mathrm{~cm}$ in diameter at the beginning of colonisation and exceeded $0.5 \mathrm{~m}$ in diameter by the end of the study. In 1976, individual potted plants (50 per plot, in $10 \mathrm{~cm}$ plastic pots) were placed in the field. All seedlings that germinated during the studies were removed by hand from the plots. At approximately 2-week intervals in 1975 , two $0.46 \mathrm{~m}^{2}$ sections of each plot were enclosed and all insects trapped within the fine mesh enclosures were removed by suction using a Dietrick sampler (Dietrick, 1961). Individual leaflets were sampled and scored according to the amount of feeding damage present on a scale of 0-6 (0 for no damage; 6, complete leaflet removal). An estimate of the

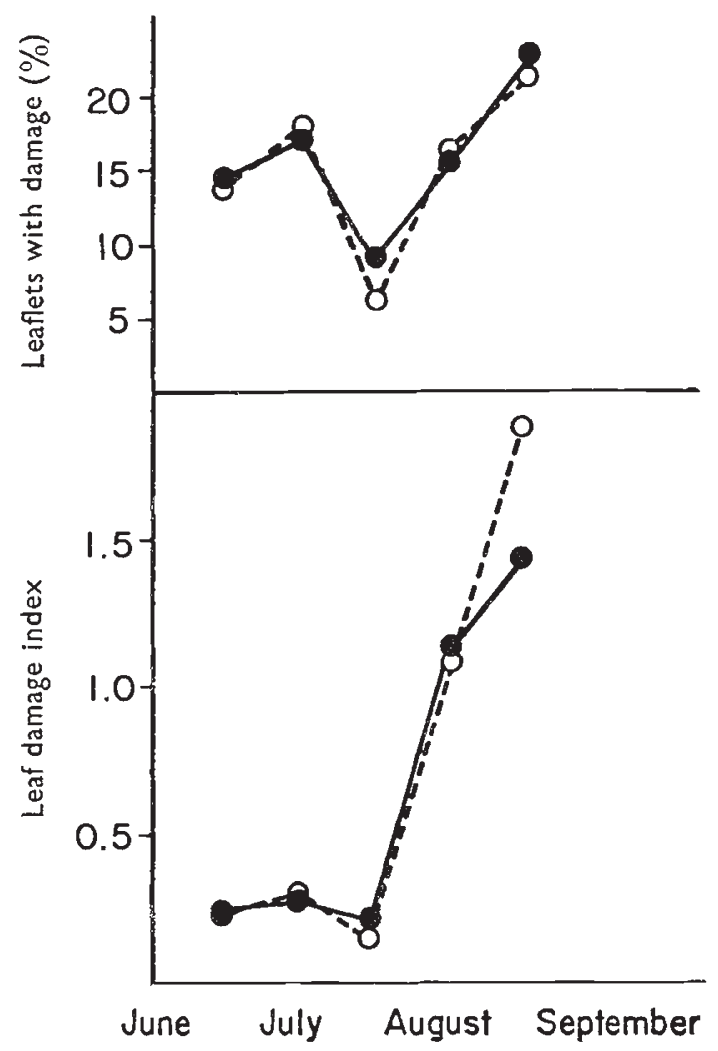

Fig. 1.-Damage recorded by insects to cyanogenic (filled circles) and acyanogenic (empty circles) plants. 
leaf biomass sampled for insects was also obtained. After the final sample in September, the plots were left undistrubed until the following May. By May, grasses had invaded all plots. An estimate of proportion of ground covered by clover was obtained for cyanogenic and acyanogenic plants.

In 1976, only colonisation by aphids was examined. After 10- and 12week colonisation intervals, the plants were enclosed in plastic bags, removed from the field, and frozen. Aphids were then separated from leaves and petioles. The leaves and petioles were oven-dried and weighed.

\section{Results}

No difference in visible feeding damage to leaves of cyanogenic and acyanogenic plants was found (fig. 1). Ants and the flea beetle, Systena frontalis, were observed causing leaf damage during the study. Other herbivores responsible for the damage observed are not known, although Orthoptera nymphs were present in the plots throughout the study and were assumed to have caused some leaf damage. Lepidoptera larvae were uncommon during the study. Mice had been excluded from the plots, while slugs and snails were notably rare on the exposed plots. Therefore, the damage observed appear to be the result of leaf-chewing insects.

Leaf damage by the end of the season was considerable. A leaf damage rating of 1.0 corresponds to roughly 10 per cent leaf area removal. The percentage of leaflets with visible feeding damage exceeded 20 per cent for both clover phenotypes by the end of the study (fig. 1). Insect herbivores, therefore, were feeding on the clover, but not discriminating between phenotypes.

The abundance of insect species that feed by sucking plant juices did not differ on the two plant phenotypes (table 1). Only three aphid species were common in the samples and these were common on both phenotypes. Other species in the leaf and stem sucking guilds were present only sporadically. Phytophagous hemiptera were particularly rare in this study. No phytophagous mites colonised the plants studied.

Homoptera (excluding the aphids) densities failed to increase in relation to plant material over the summer (fig. 2). Aphid numbers, however, increased until September (fig. 3). In August and September, aphid numbers were two to three times greater relative to plant material on acyanogenic than on cyanogenic plants. The same trend was observed for aphid numbers on potted plants in 1976 (table 2). The total numbers of aphids relative to plant material sampled was greater in 1976 than in 1975 due to the use of a more efficient sampling procedure for aphids. Differences in aphid densities on the two plant phenotypes in 1976 were significant according to a Wilcoxon ranked sum comparison, preferred because of non-normality in the data (Snedecor and Cochran, 1967).

Although differences in feeding damage to the two phenotypes were not observed, differences were observed in competitive ability with other plant species. By the spring of 1976, 72 per cent of the area formerly covered by acyanogenic plants had become overgrown with other plant species (chiefly Agropryon sp.). For cyanogenic plants, only 43 per cent of their former area was overgrown with other plant species. 
TABLE 1

Homoptera and Hemiptera species found on cyanogenic and acyanogenic plants of white clover. A plus $(+)$ indicates that the species was collected from the clover phenotype; two pluses $(++)$ indicate that the species was found in greater than 50 per cent of the samples. Non-phytophagous species are not listed

Homoptera : Aphididae Acyrthosiphon pisum Aphis craccivora Aphis craetigifoliae (?) Aphis helichrysi (?) Aphis lutescens (?) Aphis sp.

Aphis sp. Myzus persicae Myzus sp.

Nearctaphis bakeri

Therioaphis trifolii

Undetermined sp.

Homoptera : Aleyrodidae Undetermined

Homoptera : Cercopidae Lepyronia quadrangularis Philaenus spumarius

Homoptera : Cicadellidae Aceratagallia sp. Aphrodes albifrons Athysanus argentarius Chlorotettix galbanatus Chlorotettix sp.

Cloanthus actutus Cloanthus cuprescens Draeculacephala sp. Empoasca fabae Graminella fitchii Macrosteles fascifrons Macrosteles sp.

Neokolla hieroglyphica Polyamia inimica

Homoptera : Cixiidae Oliarus fransciscanus

Homoptera : Membracidae Undetermined sp.

Hemiptera : Coreidae Anasa tristis

Hemiptera : Miridae Lygus oblineatus Undetermined sp. Undetermined sp. Undetermined sp.

Hemiptera : Tingidae Corythucha marmota

Hemiptera:

Undetermined sp.
Acyanogenic Cyanogenic

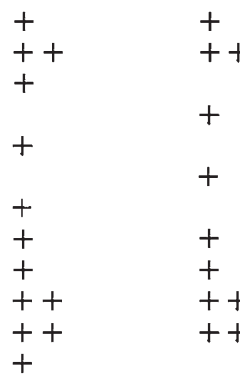

$\begin{array}{ll}+ & + \\ + & +\end{array}$

$\begin{array}{rr}+ & + \\ + & + \\ & + \\ & + \\ & +\end{array}$

$\begin{array}{ll}+ & + \\ + & \end{array}$

$+$

$+$

$\begin{array}{ll}+ & + \\ + & +\end{array}$

$+$

$+$

$+$

$+$

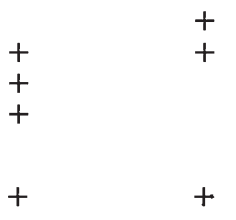

$+$ 


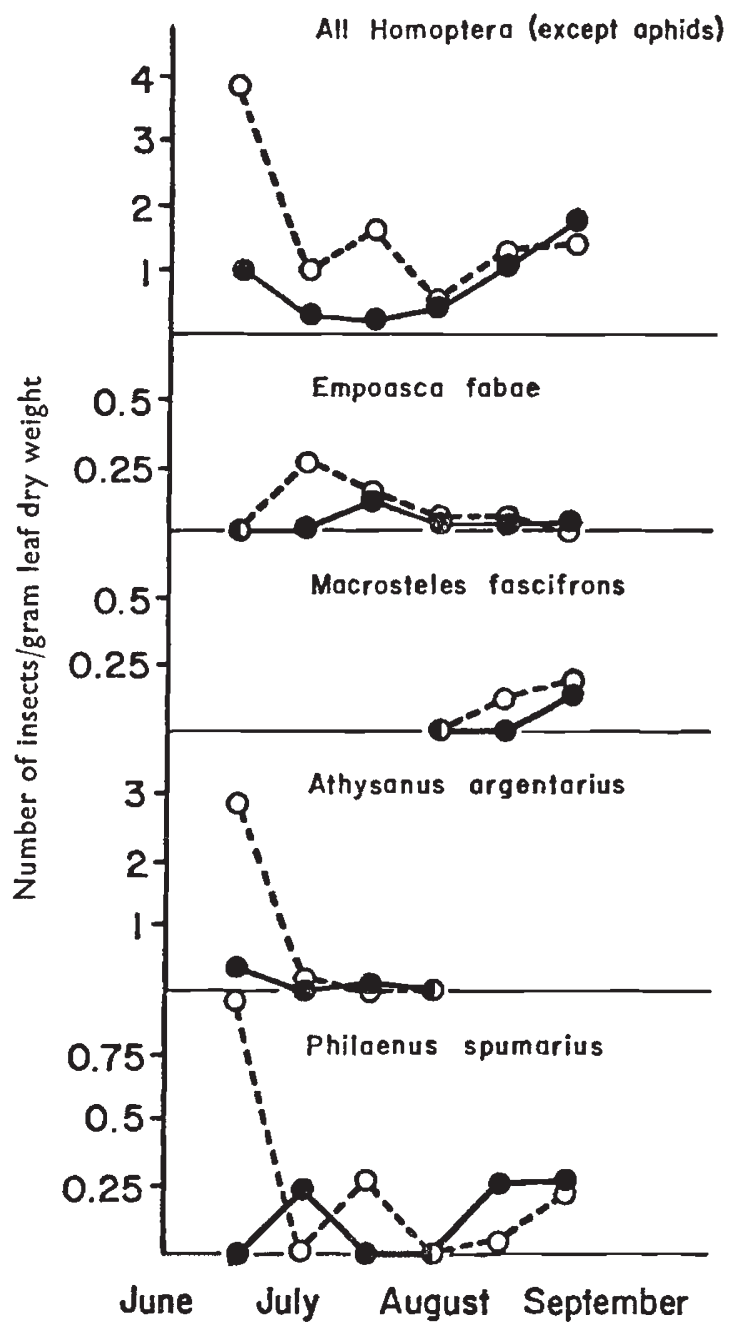

Fig. 2.-Seasonal abundances of Homoptera (excluding aphids) on cyanogenic (filled circles) and acyanogenic (empty circles) plants.

\section{Discussion}

Whitman (1973) found an inverse correlation between cyanogenesis scores (as determined by reaction with picrate) and feeding damage in wild populations of white clover. The herbivores responsible were not recorded. Angseesing and Angseesing (1973) found greater damage from slugs to acyanogenic clover plants in lawn populations. The lack of a difference in visible feeding damage in our experiment does not necessarily contradict these two studies. Slugs, which in some cases can discriminate between cyanogenic and acyanogenic phenotypes (see Crawford-Sidebotham, 1972, and Angseesing, 1974), were not responsible for the damage observed in our study. Furthermore, Whitman (1973) could have sampled feeding 
54 W. DRITSGHILO, J. KRUMMEL, D. NAFUS AND D. PIMENTEL

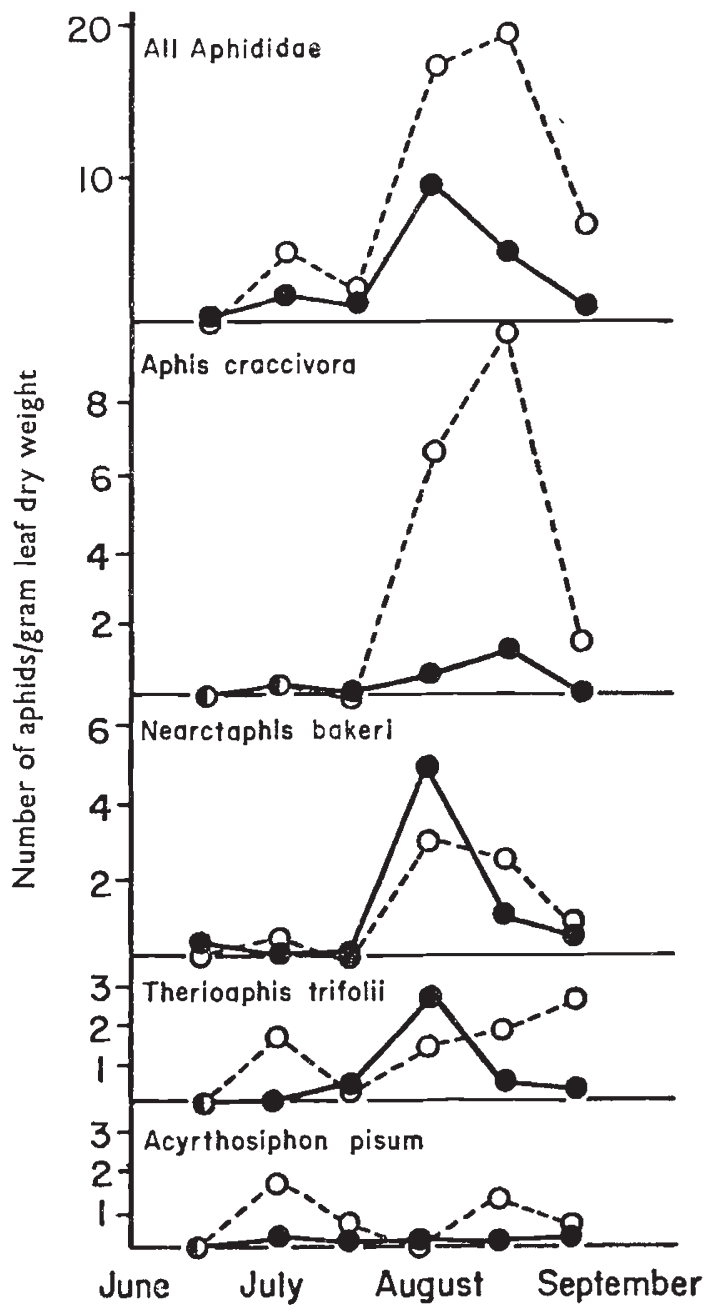

FIG. 3.-Seasonal abundances of aphids on cyanogenic (filled circles) and acyanogenic (empty circles) plants.

TABLE 2

Abundance of aphids on potted cyanogenic and acyanogenic Trifolium repens

Mean no. aphids per plant

Mean no. aphids/g

Ranked sum (no. aphids/g)

Normal variate

$n_{1}$

$n_{2}$

Significance level

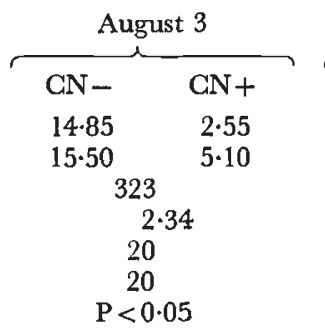

$\overbrace{\mathrm{CN}-}^{\text {August } 19} \begin{array}{cr}48.35 & \mathrm{CN}+ \\ 43.21 & 31.40 \\ 327 & 31.60 \\ 2.23 \\ 20 \\ 20 \\ \mathrm{P}<0.05\end{array}$


damage from other herbivore species that were not found in our colonising experiment. For example, white clover is a preferred host plant of Colias butterflies. We have observed that Colias species overwinter as eggs or early-instar larvae on white clover plants. The young larvae can do considerable damage to clover plants early in the growing season, but were excluded from plants studied by us using our methods.

With the exception of aphids, the insect fauna that causes cryptic leaf damage did not exhibit differences in density on the two plant phenotypes. However, except for aphids, none of the insects that feed on plant juices found in this study are common herbivores of white clover and none was present in large enough numbers to allow detection of differences-only the aphid species were present in more than 50 per cent of the samples. It is possible that a survey on a greater scale would have found different densities of insects other than aphids on the two phenotypes.

Based on our analysis it was impossible to determine what effect aphid numbers have on plant fitness. Under glasshouse conditions, aphids can quickly attain numbers sufficient to kill white clover of both phenotypes. In nature, such rapid population growth is checked by predators, parasites, and weather. Neverthless, aphid densities sufficient to retard plant growth are possible under natural conditions. The effect on fitness, however, may not be readily apparent. For example, of the plants used in the experiment, the cyanogenic phenotypes appeared to be the more vigorous competitors of other plant species, even though the growing period when no weeding was done (late fall and early spring) consisted of cold days with short photoperiods that should have favoured the acyanogenic phenotype (Daday, 1965). The greater competitive ability may have resulted from less cryptic feeding damage in the cyanogenic plants, although the possibility of allelopathy cannot be ruled out.

Crawford-Sidebothan (1972) and Jones (1972) argued that the seedling of white clover would be the most susceptible stage in the life cycle to feeding damage. Although Miller et al., (1975) failed to find evidence of differences in seedling mortality after 1 month of uncontrolled herbivory, Dritschilo and Pimentel (unpub. obs.) found that naturally occurring seedling populations of white clover had lower cyanogenesis frequencies than the surrounding adult populations. Of the insect herbivores of white clover, the colonising species in this study are the most likely herbivores of seedlings because of their ability to find new stands of clover. In our judgment, seedling mortality is not likely to result from the colonising insects studied, but herbivores, such as aphids may differentially retard the growth of seedlings of the two phenotypes. Mortality may come later from causes such as competition with other plants, but differences in mortality may ultimately be the result of different herbivore levels.

In conclusion, selection by some insect species against the acyanogenic phenotype may be added to a growing list of selective agents involved in the cyanogenesis polymorphisms: vertebrate and molluscan herbivores, temperature (Daday, 1965), and soil moisture (Foulds and Grime, 1972). Ellis et al. (1977), have clearly shown that the defensive role of cyanogenesis in Lotus corniculatus is an important one, contrary to still-prevalent views that the main function of cyanogenesis is nitrogen storage (Seigler, 1977). The insect fauna of Lotus corniculatus is possibly greater than that on Trifolium repens (Nunzig and Gyrisco, 1955, reported fewer herbivore species than in 
this study, but all were in greater abundance-with the exception of aphidsthan the species listed in this study) and offers an interesting prospect for further work on this polymorphism.

Acknowledgments.-This research was supported in part by a grant from the National Science Foundation (Ecology DEB 77-05322). The assistance of Michael Burgess, John Gowan, and Ric Hill is gratefully acknowledged.

\section{REFERENCES}

Angseesing, J. P. A. 1974. Selective eating of the acyanogenic form of Trifolium repens. Heredity, 32, 73-83.

ANGSEESING, J. P. A., AND ANGSEesing, W. J. 1973. Field observations on the cyanogenesis polymorphism in Trifolium repens. Heredity, 31, 276-282.

BERNAYS, E. A., CHAPMAN, R. F., LEATHER, E. M., MCCAFFERY, A. R., AND MODDER, W. W. D. 1977. The relationship of Zonocerus variegatus (L.) (Acridoidea : Pyrgomorphidae) with cassava (Manihot esculenta). Bull. Entomol. Res., 67, 391-044.

COOPER-DRIVER, G. A., AND sWAIN, T. 1976. Cyanogenic polymorphism in bracken in relation to herbivore predation. Nature, $260,604$.

CRAWFORD-SIDEBOTHAM, T. J. 1972. The role of slugs and snails in the maintenance of the cyanogenesis polymorphisms of Lotus corniculatus and Trifolium repens. Heredity, 28, 405-411.

DADAY, н. 1965. Gene frequencies in wild populations of Trifolium repens L. IV. Mechanism of natural selection. Heredity, 20, 355-365.

DIETRICK, E. J. 1961. An improved back pack motor fan for suction sampling of insect populations. F. Econ. Ent., 52, 1085-1091.

ELLIS, W. M., KEYMER, R. J., AND JONES, D. A. 1977. On the polymorphism of cyanogenesis in Lotus corniculatus L. VIII. Ecological studies in Anglesey. Heredity, 39, 45-65.

FOULDS, W., AND GRIME, J. P. 1972. The influence of soil moisture on the frequency of cyanogenic plants in populations of Trifolium repens and Lotus corniculatus. Heredity, 28, $143-146$.

JONEs, D. A. 1962. Selective eating of the acyanogenic form of the plant Lotus corniculatus L. by various animals. Nature, 193, 1109-1110.

JONEs, D. A. 1966. On the polymorphism of cyanogenesis in Lotus corniculatus. I. Selection by animals. Can. 7. Genet. Cytol., 8, 556-567.

Jones, D. A. 1972. Cyanogenic glycosides and their function. In Phytochemical Ecology, ed. J. B. Harborne, pp. 103-124. Academic Press, London.

LANE, c. 1962. Notes on the common blue (Polyommatus icarus Rott.). Egg laying and feeding on the cyanogenic strains of bird's foot trefoil (Lotus corniculatus L.). Ent. Gaz., 13, 112-116.

MILLER, J. D., GIBSON, P. B., COPE, w. A., AND KNIGHT, W. E. 1975. Herbivore feeding on cyanogenic and acyanogenic white clover seedlings. Crop Sci., 15, 90-91.

NUNZIG, H. N., AND G. G. GYRIsCo. 1955. Some insects injurious to birdsfoot trefoil. 7. Econ. Ent., 48, 447-450.

SCRIBER, J. M. 1978. Cyanogenic glycosides in Lotus corniculatus. Their effect upon growth, energy budget, and nitrogen utilization of the southern armyworm, Spodoptera eridania. Oecologia, 34, 143-155.

SEIGLER, D. s. 1977. Primary roles for secondary compounds. Biochem. Syst. Ecol., 5, 195-199.

SNEDECOR, G. W., AND COCHRAN, w. G. 1967. Statistical Methods, 6th Ed. Iowa State University, Ames, Iowa.

whitMan, R. J. 1973. Herbivore feeding and cyanogenesis in Trifolium repens L. Heredity, $30,241-244$.

WOODHEAD, S., AND BERNAYS, E. 1977. Changes in release rates of cyanide in relation to palatability of Sorghum to insects. Nature, 270, 235-236. 